\title{
O jogo autor-leitor na literatura do agora
}

\author{
Everton Vinicius de Santa ${ }^{1}$
}

\begin{abstract}
O passado nunca está morto. Ele nem sequer é passado.
\end{abstract}
Faulkner

Pensar a literatura, seja ela contemporânea ou não, implica deparar-se com questões atemporais que envolvem, sobremaneira, autor, leitor e obra. Além disso, embora muito possa ser dito acerca da memória como elemento condutor da narrativa, como é o caso de Dom Casmurro (1889), de São Bernardo (1934) e de Grande sertão: veredas (1956), entre outras já com muita fortuna crítica, a questão fulcral (e problemática) ainda a ser tratada no que se refere à nossa literatura atual, essa dos anos de 1990 até hoje, é buscar entender por que os autores contemporâneos, da literatura impressa e da digital, precisam tanto de uma exposição midiática e, aparentemente, usam dessa exposição para justificar suas escolhas na criação da obra literária. Isso gera, portanto, um fato interessante: o leitor querendo saber de onde vem a história narrada, de certa maneira reiterando ou retroalimentando o foco sobre a obra do autor. Em tempos de "literatura por encomenda", como é o caso do projeto Amores expressos, ${ }^{2}$ o mercado editorial tem tanto peso quanto o leitor que consome essa literatura.

Esse é um novo jogo, com certeza, embora iniciado já no passado com os prefácios de autores (especialmente nas segundas edições) a justificarem e responderem às críticas que tiveram de outros leitores. Hoje, os escritores estão cada vez mais em evidência e acessíveis, sobretudo, se considerarmos a imersão desses sujeitos (autores e leitores) no ciberespaço por meio de redes sociais ou mesmo em eventos acadêmicos. Logo, o jogo vai além do texto, além do autor, e do próprio leitor, e consolida a ideia mítica que pairava sobre o processo criativo literário ou sobre a questão da autoria. A arte não perde seu estado metafísico, na medida em que ainda provoca estranhamento. Ela, no entanto, está longe de um plano demiúrgico já há algum tempo.

Além disso, a concepção de autor já esteve ligada à ideia do trabalho artístico elaborado, ao trabalho estético, que resultava na elaboração

\footnotetext{
${ }^{1}$ Doutorando em literatura da Universidade Federal de Santa Catarina (UFSC), Florianópolis, SC, Brasil. E-mail: evertonrep@yahoo.com.br

2 Disponível em: <http://www.companhiadasletras.com.br/busca.php?b_categoria=096\&b_filtro=livro>. Acesso em: 20 set. 2011.
} 
de textos mais tarde canonizados, marcados por um individualismo de ideias que culminavam na "imortalidade" do sujeito-autor diante de sua obra. Dessa relação autor-texto emergiu a figura do cânone, dignificada e desmitificada diante das práticas de leitura e escrita presentes na contemporaneidade. Benjamin (1985) já idealizava isso na primeira versão de seu texto, escrita entre 1935 e 1936, sobre a "reprodutibilidade técnica". O autor, grosso modo, perdeu sua aura mitificada e estabeleceu contato direto com o leitor, o qual, certamente, contribui para parte do processo.

Percebam que tenho chamado a atenção para uma literatura que permeia o impresso e o digital justamente porque considero essas relações cada vez mais indissociáveis de uma produção atual de literatura envolvendo os artifícios e possibilidades de construção e consumo do texto. Não obstante, mais adiante, tratarei da relação autor-leitor com base em um romance impresso, cujas alusões serão pertinentes às discussões. Além disso, não podemos deixar de lado o fato de que essas "textualidades contemporâneas" têm seu peso sobre as produções culturais:

As novas tecnologias direcionam vários campos da produção cultural. Direcionam a cultura. Criam a cibercultura. [...] Assim, refletir como o homem se relaciona com a máquina, de forma inversa a qual preconizou McLuhan, pensando a dinâmica tecnológica e não mais a leitura determinista, parecer ser o caminho para compreender o autor como um personagem pela comunicação entendido e estendido, adotado pelo meio e redefinido pela preocupação que passa o homem hoje a ter com as novas invenções (Oliveira Filho, 2009, p. 143).

Nesse sentido, é importante reiterar que as mudanças na literatura impressa frente à literatura em meio digital fizeram com que a arte literária fosse cada vez mais questionada com relação ao seu papel, antes dignificado pela alta cultura e, por vezes, entregue ao superficialismo, aos temas ridículos e à falta de literariedade. Na verdade, essas transformações deveriam ser observadas criticamente como uma tendência da tecnologia textual que configura aspectos das práticas de escrita e que merecem atenção por estarem ligados diretamente ao processo de criação literária na contemporaneidade.

Ao tratarmos das literaturas nos dois meios, impresso e digital, nos deparamos com a questão dos gêneros, por exemplo. Para Genette (1986), estes se transformam com o passar do tempo e passam por um processo de hibridização e de "atualização". Logo, todo gênero pode conter outros gêneros numa relação de simbiose ou hibridismo como acontece muito no meio digital, por exemplo, com blogues que apresentam outros gêneros em sua estrutura, e no meio impresso quando nos deparamos com um romance (já entendido como um gênero 
híbrido desde suas origens) $)^{3}$ que apresenta cartas, poemas, figuras, letras de música e outros elementos em sua estrutura. Os escritos em meio digital vêm corroborar a tese genettiana em função de sua pluralidade discursiva, algo que acontece também na literatura impressa:

Não existem arquigêneros que escapem totalmente à historicidade conservando ainda uma definição genérica. Existem modos, exemplo: a narrativa; existem gêneros, exemplo: o romance; a relacionalização dos gêneros com os modos é complexa, e sem dúvida que não é, como sugere Aristóteles, de simples inclusão. Os gêneros podem atravessar os modos (Édipo contado permanece trágico), talvez como as obras atravessam os gêneros (Genette, 1986, p. 84).

Em nosso atual momento de produção literária, sobretudo na literatura dos anos 2000, observamos práticas de escrita sobre si, envolvendo técnicas de criação narrativa focadas no "eu", na memória e na vida literária do sujeito-autor ("homem empírico"), o que podemos entender como sendo uma tendência literária de criação romanesca que se fundamenta na memória, no ato de rememoração e no imediatismo, ao mesmo tempo em que preza por uma "publicização" e exposição da figura de si.

Essas escritas sobre si revelam uma construção e preservação da memória que constituem um processo presente entre as práticas sociais cujo registro de fatos, impressões e representações de si e de seu meio possibilitam que os sujeitos, além de vivenciarem o presente, vejam nele seu processo de amadurecimento, tanto por meio da literatura, documentos, imagens, sons, quanto por meio dos atuais bancos de dados disponibilizados no ciberespaço.

Considero importante tratar do armazenamento e preservação da memória ao abordar os meios impresso e digital, sobretudo, porque esse processo é um dos aspectos evidenciados pelos escritos e pelas atividades que envolvem esse ambiente virtual e dinâmico. Nesse sentido, podemos considerar que os sujeitos-autores levam em consideração a exposição midiática a que estão submetidos para justificarem suas escolhas quando escrevem.

Contudo, não podemos restringir esse aspecto apenas ao meio digital, como bem aponta Santos (1996), uma vez que estamos tratando da criação do texto, ou seja, não podemos atribuir um valor de "ineditismo" quanto a esse aspecto:

É realmente difícil compreender como se pode refletir acerca das "textualidades contemporâneas", a partir de uma recusa obstinada em admitir a emergência de novos paradigmas, a partir de uma utilização seletiva de tecnologias (utilizam-se as técnicas advinda

${ }^{3}$ Sobre isso, ver Stalloni (2003). 
da escrita e da imprensa, mas se recusam as novas tecnologias em nome de um purismo passadista) (Santos, 1996).

Tomando como um exemplo o romance Cidade livre (2010), de João Almino, observamos um narrador que escreve suas memórias e, logo na introdução, inicia um jogo: primeiro, com a questão da autoria, segundo, com uma hibridização de gêneros declarada quando diz que resolveu escrever um blogue por falta de editora para publicar seu livro (já impresso, porque estamos com ele nas mãos, lendo). Esse jogo a que me refiro está no processo de criação da obra e pode ir além de uma simples escolha "paródica" do tema memória e do jogo com o leitor.

Assim, o jogo que trata das questões de literatura e autoria contemporânea a que me refiro desde o início deste ensaio e suas relações com o leitor nortearão minhas considerações a partir de então. Um erro emocional (2010), de Cristovão Tezza, nos permitirá refletir sobre essas relações.

\section{Um romance contemporâneo}

Fala-se muito nessa literatura contemporânea pautada no fragmento, aquele do homem, do ser, da vida, da memória que, na verdade, se constitui aos pedaços. Essa mesma literatura, dita contemporânea porque do nosso presente, se desdobra em vários caminhos temáticos, estruturais, estilísticos e ideológicos, mas que evidenciam (quase) sempre uma escrita que fala sobre um "eu", por vezes nas entrelinhas e mais evidente quando nos deparamos com autobiografias e discursos trançados por meio da memória, do ato de rememorar, como em Heranças (2008), de Silviano Santiago, Cidade livre (2010), de João Almino, Leite derramado (2009), de Chico Buarque, e uma série de outras obras permeadas por essa necessidade de rememorar.

Um erro emocional se pauta nas impressões do "agora", nas lembranças do "há pouco", e faz um exercício constante de idas e vindas que se caracteriza por elementos fluindo entre as impressões e percepções de Beatriz e Paulo, do "eu" e do "outro". O leitor assiste de camarote e se perde no meio desse emaranhado jogo de ditos e velados. O diálogo começa com a inusitada confissão e desenrola um papiro de lembranças sobre as mais variadas situações, da infância aos relacionamentos amorosos atuais, tudo em apenas uma noite, em Curitiba, tempo que envolve pizza, vinho, chá, café e poucas palavras. Sim, muito poucas.

Cometi um erro emocional, Beatriz se imaginou contando à amiga dois dias depois - foi o que ele disse assim que abriu a porta, o tom de voz neutro, alguém que parecia falar de uma avaliação da Bolsa, avançando sem me olhar como se já conhecesse o apartamento, 
dando dois, três, quatro passos até a pequena mesa adiante em que esbarrou por acaso, depositando ali o vinho com a mão direita e a pasta de textos com a esquerda (e ela se viu desarmada no meio de três sinais contraditórios, o erro, o vinho, o texto, mais a espécie de invasão de alguém que está à vontade - o que havia sonhado, Beatriz teria de confessar à amiga, e ambas achariam graça da ideia - à vontade, mas não do modo correto) e Beatriz fechou a porta devagar como um sorriso de quem se vê imersa na ironia, e isso é bom; e se virou para escutar o resto, agora vendo-o com as mãos livres, a silhueta contra a luz, os braços brevemente desamparados daquele homem magro: - Eu me apaixonei por você (Tezza, 2010, p. 7).

O romance tem muito movimento, gestos e cheiros que transportam, ora Beatriz, leitora, ora Paulo Donetti, escritor, aos seus passados e às suas impressões sobre suas falas e expectativas. Logo, o diálogo pouco se vê (ou se lê). Na verdade, muita coisa fica "por dizer". Há um tom de verossimilhança com aquilo que podemos chamar de "cuidado com as palavras", sobretudo, em relacionamentos afetivos. Uma "quase-história" de amor moderna, que poderia ter acontecido ontem mesmo, tipicamente contemporânea em sua construção narrativa, sufocante, fragmentária e, claro, sem surpresas no final.

Paulo é escritor, paulista, quarenta e dois anos, que surge como um intelectual promissor e vira apenas uma promessa não cumprida. Tempos difíceis para se viver de literatura, segundo ele. Vem de fracassos literários, embora seja reconhecido, e de fracassos pessoais. Vive aqui e ali, ganhando a vida com palestras e pequenas publicações. Lamenta as críticas negativas aos seus livros, sente que a mediocridade o ronda. Beatriz, curitibana, é bem mais jovem e carrega culpas, que incluem a morte acidental dos pais e a traição recíproca dela e do ex-marido.

Os dois se conheceram durante um jantar entre amigos. No dia seguinte, Paulo aparece no apartamento da admiradora (Beatriz) com um vinho, uma pasta de textos e uma declaração fria. Ele estava em Curitiba apenas de passagem e resolve ficar mais um pouco na cidade, afinal, apaixonado por Beatriz e tentando aproximar-se de sua admiradora, pede que ela o ajude na revisão de seu novo livro: "Eu preciso - é isso, essa a palavra eu preciso de uma leitora, no sentido pleno da palavra... - Você é a melhor leitora que jamais encontrei" (Tezza, 2010, p. 28). Já aqui percebemos o jogo que irá se construir sobre a relação entre autor e leitora, porém, já sem mitificação do status do autor empírico, visto que o que será colocado em relevo é o sujeito-autor do texto, aquela instância que narra e que é uma construção intrínseca ao plano textual. Além disso, Paulo se vê diante de uma leitora assídua e conhecedora de seu trabalho. Por isso, a necessidade de um contato mais direto com Beatriz, essa leitora "plena". 
Logo no início da leitura, podemos pensar que Um erro emocional seria uma história de amor, dessas que se vê sempre por aí na literatura. Pelo contrário: Paulo e Beatriz pouco se falam e pouco se tocam. Raramente suas mãos se esbarram aqui e ali, leve e rapidamente. Essa reticência é expressa pela construção dos personagens, que parecem estar na expectativa, rememorando consigo mesmo seu passado, ansiando compartilhar as lembranças um com o outro, mas essa ânsia fica velada, no silêncio. No plano da diegese, ${ }^{4}$ Paulo e Beatriz pouco sabem da vida um do outro, mas nós, leitores, ficamos sabendo de muita coisa.

Esse movimento de invasão do leitor e de evasão dos personagens é tecido por um discurso próximo ao do monólogo interior, aquele que habita o (in)consciente dos personagens e confunde as focalizações da narrativa. Esse recurso faz parte do jogo narrativo e recai sobre o leitor, levando -o à cuidadosa tarefa de perceber os níveis pelos quais está percorrendo, se o do texto, se o dos personagens. Por isso, os parágrafos são longos nas trinta e seis partes em que o narrador onisciente nos conta a história de Beatriz e Paulo.

O romance trata de uma relação (quase amorosa) entre duas pessoas já carregadas de histórias pessoais e, naturalmente, rondadas por elas. Beatriz perdeu o pai, a mãe e o irmão em um acidente de carro durante uma viagem da qual ela foi forçada a não participar em função de uma prova no curso de Letras. Paulo, por sua vez, é um escritor reconhecido e guarda no histórico uma miserável inveja do amigo a quem ajudou a lançar o primeiro livro e que depois ganhou fama. Ambos já experimentaram o divórcio e é interessante como o passado se faz presente e recorrente no "discurso do agora", afinal, são as memórias que os levam ao passado. Mas que espécie de influência é essa do passado sobre o presente e sobre a vida? Ora, "todo instante presente existe apenas em função de seu passado, aquilo que de fato cria o tempo, o peso da lembrança" (Tezza, 2011), nas palavras do autor em entrevista recente.

Se o discurso do romance transita entre presente e passado (no plano das ideias), então, podemos dizer que seus personagens vivem à sombra de seu passado, que se reflete, sobremaneira, em suas ações e conviç̧ões do presente. Há uma troca de confissões veladas entre os dois, embora não falem diretamente um ao outro, em função do fluxo de pensamento que observamos durante a leitura. Nesse sentido, constatamos que os mecanismos de memória como parte constituinte da composição discursiva dos sujeitos (sejam eles personagens ou não) é inevitável.

\footnotetext{
4 Entendo aqui como diegese a realidade própria da narrativa ("mundo ficcional", "vida fictícia"), à parte da realidade externa de quem lê (o chamado "mundo real"). Ver Genette (1980).
} 
Esse discurso fragmentado presente na narrativa de Tezza deflagra uma corrente de pensamentos e dizeres não ditos que ficam atrelados ao interior de suas duas personagens-chave. Esses "pedaços de memória" que ficam ou se perdem talvez sejam os que mais representam a ideia de indivíduos (sujeitos) fragmentados, caracterizando uma multiplicidade de "eus" em busca de si mesmos e na tentativa de preservar sua memória por meio do "outro", constituindo assim uma relação de alteridade. Esse julgamento do outro fica evidente o tempo todo na narrativa, haja vista o cuidado que se tem com o que será dito e, por isso, as falas das personagens resumem-se a frases curtas e muitas vezes não desenvolvidas, erráticas. Essa relação do "eu com o outro" é de reciprocidade, uma vez que o "eu" só existe se o "outro" lhe materializa, seja no discurso, seja no plano das ideias.

Sobre a memória, então, a consideramos parte constituinte do sujeito -eu (e aqui referimo-nos à narrativa de Tezza), que se manifesta como um reflexo autoafirmativo sobre si mesmo. Afinal, entender o ato de existir, muitas vezes, pode se resumir a um começo, meio e fim, daí refletir sobre a memória como um modo de preservar a figura do "eu", não apenas em nível pessoal, mas também cultural, se pensarmos na sociedade como um organismo único e em tudo o que está registrado sobre suas experiências: Pensar a questão do arquivo (impresso e eletrônico) dialoga com uma reflexão sobre o poder em sua essência. Poder de disponibilizar instrumentos de permanência de certos sentidos, de recolher ou aniquilar a memória, de burocratizar e oficializar informações, de construir lugares de resistência, de autorizar que alguns sentidos sejam divulgados e outros não, de servir para que algumas vozes sejam caladas ou insurjam na infomaré. [...] O sujeito na malha digital é aqui compreendido como sujeito do discurso em relação a um poder, posição inscrita pela ideologia e pela memória... (Romão, 2008, p. 162).

A necessidade, por parte dos indivíduos, de preservar ou tratar de sua memória talvez esteja justamente ligada ao fato de que, em meio a tantos registros de fatos e pessoas, voltar-se para a singularidade de sua própria existência pode ser uma forma de apresentar-se ao "outro" como parte constituinte e distinta em meio ao todo, como muitas vezes percebemos na relação que se constrói entre os personagens Paulo e Beatriz, ambos em um processo de autorização mútuo de acesso às suas memórias, ainda que por um filtro, já que apenas o leitor tem acesso livre a elas.

Por meio dessas lembranças, o narrador transita entre os diálogos e pensamentos dos dois personagens. Isso chega a nos causar uma sensação de "asfixia", uma vez que somos levados dos risos, suspiros e olhares até os indícios de que, se palavras não estão sendo ditas, é certo que elas estão correndo de um lado para outro na mente dos dois. A maior parte das 
frases que aparece é simples, quase lacônica, constrangedora para ambos. Mesmo os pensamentos são constantemente cortados, atropelados por outros. Momentos marcantes do passado e momentos estáticos do presente revezam-se na trama do discurso indireto-livre. O ponto de vista desloca o leitor o tempo todo de um personagem para outro:

- Mas - e ela prendeu o lábio com os dentes, suspeitando que invadia demais a vida dele; melhor mudar de assunto, puxá-lo para a mesa e para as folhas amarelas de novo, mas ela não resistia - você acha que sua relação com Antônia (eles foram casados? O silêncio de Donetti era um silêncio cada vez mais tenso que ela não conseguia decifrar) - Beatriz ia dizer desandou - foi afetada pela - ela ia dizer presença - pela sua amizade com o Cássio? - Sim. A Tina (Tezza, 2010, p. 97).

Interessante notar ainda que Paulo confere um tom metaficcional à trama de Tezza, uma vez que é um personagem escritor. Trata-se de uma narrativa metaficcional, na medida em que tanto Paulo quanto o "ato da escrita" são partes integrantes do enredo e da relação autor-leitor, a qual é, inclusive, discutida pelos personagens do livro - "para um escritor a felicidade, pelo menos a dos outros, é a morte do texto" (Tezza, 2010, p. 102) -, algo muito próximo do que afirma Barthes:

[O] leitor é o espaço exato em que se inscrevem, sem que nenhuma se perca, todas as citações de que uma escrita é feita; a unidade de um texto não está na sua origem, mas no seu destino, mas este destino já não pode ser pessoal: o leitor é um homem sem história, sem biografia, sem psicologia; é apenas esse alguém que tem reunidos num mesmo campo todos os traços que constituem o escrito... O nascimento do leitor tem de pagar-se com a morte do Autor (Barthes, 2004, p. 5).

É claro que esse "polemizado" texto de Barthes, ao lado do questionamento de Foucault (2002), coloca em xeque (ou em foco) a demiúrgica figura clássica do autor do texto literário. A relação entre Beatriz e Paulo vem ao encontro dessa dessacralização da concepção de autor intocável e, por certo, traz à tona essa discussão sobre o distanciamento do autor, do texto e do leitor no plano da diegese.

\section{Uma literatura em movimento}

Se antes a figura do autor, de autoridade, era colocada em um pedestal, aos poucos essa noção foi se transformando, e não me refiro aqui à Estética da Recepção, que propõe uma reformulação da historiografia e da interpretação textual, da relação dinâmica autor, obra, leitor, mas, sim, da relação entre a obra e a pessoa física do autor empírico, que vem se tornando 
uma figura cada vez mais sólida e acessível, sobretudo, por estarmos interagindo em um mundo informatizado, desterritorializado, ${ }^{5}$ móvel.

Permitam-me fazer um esclarecimento sobre o adjetivo "móvel", estritamente ligado ao ciberespaço. A relação entre o trinômio autor, obra, leitor e as possibilidades de interação entre essas instâncias são propiciadas por práticas eletrônicas de leitura e produção de literatura. Essa é a ideia da mídia em movimento em que "o mundo contemporâneo é caracterizado pela mobilidade cultural, definida como atos de transferência através dos quais um agente transfere um objeto cultural de um sistema a outro em um contexto histórico concreto" (Moser apud Walty, 2007, p. 196), ou seja, há um trânsito evidente que podemos correlacionar às manifestações culturais como um todo, muito próximo do sentido da intertextualidade ou dos palimpsestos. ${ }^{6}$

Quanto ao ciberespaço e às mídias contemporâneas, Moser propõe a investigação desse movimento em três campos e conceitua "locomoção", "midiamoção" e "artemoção" (Bahia, 2009, p. 13). Para os estudos de literatura e informática, o conceito de "midiamoção" é essencial para entendermos essa noção de movimento, uma vez que ele está relacionado com as mídias sociovirtuais (uma referência às redes sociais), suas influências no processo criativo e no trânsito do cenário pós-moderno (ou pós-humano), que se resume ao simples ato de sentar-se em frente à tela de um computador: "O ser humano pode estar fisicamente imóvel, é o mundo midiatizado que está em movimento na tela e que desfilando interpela pelo nosso aparelho sensorial" (Bahia, 2009, p. 13).

Logo, são essas possibilidades de acesso e comunicação que fazem as concepções de autoria e leitor corroborarem níveis de interferências e influências no processo criativo da obra ou mesmo na constituição de uma fortuna crítica, seja ela acadêmica ou não. No caso de Donetti, certamente, a realimentação que ele buscava em Beatriz, embora um pretexto para aproximar-se dela, evidencia a relevância desse retorno que o escritor tanto anseia sobre sua obra, necessidade suprida e alimentada pelo fácil acesso e contato com o leitor. Claro que o encontro entre os dois personagens não se deu de modo virtual, contudo, quero reiterar como esse desejo ou necessidade facilmente observada em blogues, por exemplo, é possibilitada pelos ambientes virtuais.

Beatriz nutria uma admiração (ou paixão) pelo autor que lia, mas a figura física do autor que escreve é diferente do narrador que fala, como

\footnotetext{
${ }^{5}$ Termo utilizado por Deleuze e Guattari (1995), em Mil platôs, lançado em 1980, e que nos é atual, afinal, marca a chamada sociedade pós-moderna, dominada pela mobilidade, pelos fluxos, pelo "desenraizamento" e pelo hibridismo cultural presente no ciberespaço.

6 "O palimpsesto é uma imagem arquetípica para a leitura do mundo. Palavra grega surgida no século V a.C., depois da adoção do pergaminho para o uso da escrita, palimpsesto veio a significar um pergaminho do qual se apagou a primeira escritura para reaproveitamento por outro texto" (Pesavento, 2004, p. 26).
} 
nos ensina a teoria da narrativa. Como estudante de Letras que havia sido, ela sabia disso. Ao se conhecerem, ambos entram em um emaranhado jogo que já não está mais na relação da "função-autor" e mais uma vez vem evidenciar a influência (ou necessidade?) dessa exposição midiática e da escrita colaborativa nas práticas atuais de literatura. Há quem diga que a "morte do autor" se concretizou quando os escritos a várias mãos começaram a aparecer nas comunidades do orkut (assim, com minúscula mesmo, conforme Foggetti, 2008) ou quando os autores de blogues de ficção pediam aos seus leitores que lhe sugerissem rumos para a história que estava sendo contada. Mas essa é uma discussão para outro momento.

Paulo Donetti, por sua vez, não faz diferente. Embora estejamos falando de um livro impresso, de papel e capa, há a preocupação em ter esse dedo do leitor metido ali no seu processo criativo:

- O que eu queria dizer -...é que no Brasil não temos a tradição tout court, de alguém que lê e sugere, um olhar de fora, aqui para que Que o escritor tem de descobrir tudo sozinho, e é assim mesmo que eu sempre quis - e ele se empertigou num segundo tenso, o que ela percebeu, recolhendo lenta a página amarela tentando descobrir o que estaria acontecendo, mas o próprio Donetti desfez a couraça com um suspiro: - Bem, agora, e ele parecia procurar a palavra agora eu me entrego. Acho que você - e mais uma vez ele procurava a palavra - é a pessoa - e ele frisou - perfeita (Tezza, 2010, p. 61).

\section{A arte literária em mão dupla: autor e leitor}

Para além das discussões teóricas, o que se acompanha em Um erro emocional não é meramente o diálogo entre os dois personagens, mas, sim, uma desconstrução da vida daquelas duas pessoas. Cada frase, cada entonação e, muitas vezes, cada palavra que ambos utilizam nesses diálogos traz uma lembrança, um fato, uma marca do passado. Por meio de um diálogo comum, Tezza molda dois personagens profundamente, adaptando sua linguagem ao fluxo de pensamentos de qualquer ser humano: delirante, lacônico, associativo e, ao mesmo tempo, interrompido o tempo todo.

O que Tezza faz é um desvio desse ato corriqueiro - um encontro entre duas pessoas no qual nem sempre se diz o que se pensa -, aliando técnica e estrutura narrativa para manter não só o ritmo, mas também a curiosidade do leitor, que aparece no livro quase como Doralice, a amiga, para quem Beatriz contará a história no dia seguinte. Se culpa, se erro, se desvio, enfim, talvez Paulo esteja se culpando até agora por ter se apaixonado por Beatriz. Nunca se saberá como essa história terminou. 
Desse modo, o romance de Tezza nos permite visualizar um processo que contempla a relação simbiótica autor-leitor no sentido de sua atual conjectura, ou seja, o autor buscando a retroalimentação de sua produção por parte de seu leitor, algo que, alguns séculos atrás, era uma prática pouco visualizada, mas não inexistente. Isso nos demonstra que, em tempos de exibicionismo midiático e autoafirmação, a literatura dita contemporânea, essa dos nossos dias, tem em seu cerne um rol de autores já desmitificados e sofrendo influências de seus leitores, figura que quase sempre esteve à margem do processo criativo porque adotava uma postura contemplativa diante da obra literária, embora criasse sua própria obra no ato de leitura, como ainda acontece.

Contudo, não podemos deixar de observar que as instâncias autor e leitor representam papéis significativos nos processos que envolvem a arte literária atual, uma evolução de posturas e perspectivas resultantes tanto das facilidades propiciadas pelo ciberespaço, quanto pela fluidez e velocidade com que temos nos relacionado em nosso mundo real.

\section{Referências}

BAHIA, Marcio (2009). Mídias em movimento: o conceito de midiamoção e a indústria do entretenimento. In: WALTY, Ivete; CURY, Maria; ALMEIDA, Sandra (Orgs.). Mobilidades culturais: agentes e processos. Belo Horizonte: Veredas \& Cenários.

BARTHES, Roland (2004). O rumor da língua. São Paulo: Martins Fontes.

BENJAMIN, Walter (1985). A obra de arte na era da sua reprodutibilidade técnica. In: Obras escolhidas I: magia e técnica, arte e política. São Paulo: Brasiliense.

DELEUZE, Gilles; GUATTARI, Félix (1995). Mil platôs: capitalismo e esquizofrenia. São Paulo: Editora 34.

FOUCAULT, Michel (2002). O que é um autor? Lisboa: Vega.

FOGGETTI, Maria Janaina (2008). Pedaços de literatura: criação e crítica no orkut. In: CORRÊA, Alamir Aquino (Org.). Ciberespaço: mistificação e paranóia. Londrina: UEL. GENETTE, Gérard (1980). Narrative discourse: an essay in method. New York: Cornel University Press.

(1986). Introdução ao arquitexto. Lisboa: Vega.

OLIVEIRA FILHO, Wilson (2009). Desconstruindo McLuhan: o homem como (possível) extensão dos meios. Rio de Janeiro: E-papers. Disponível em: <http://migre. me/5yZ40>. Acesso em: 4 mai. 2012.

PESAVENTO, Sandra J. (2004). Com os olhos no passado: a cidade como palimpsesto. Esboços, Florianópolis, v. 11, n. 11, p. 25-30. Disponível em: <http://migre. me/2gIb4>. Acesso em: 15 ago. 2011.

ROMÃO, Lucília Marília Souza (2008). A autoria na rede eletrônica. In: TFOUNI, Leda Verdiani (org.). Múltiplas faces da autoria: análise do discurso, psicanálise, literatura, modernidade e enunciação. Ijuí: Editora Unijuí. 
SANTOS, Alckmar Luiz dos (1996). Textualidade literária e hipertexto informatizado. NUPILL, Florianópolis. Disponível em: <http:/ / migre.me/5yLuw >. Acesso em: 5 maio 2012.

STALLONI, Yves (2003). Os gêneros literários. Rio de Janeiro: DIFEL. TEZZA, Cristovão (2010). Um erro emocional. São Paulo: Record. (2011). Entrevista com Cristovão Tezza - Um erro emocional. Livrada!, 2 fev. Disponível em: <http:/ / migre.me/4ISYg>. Acesso em: 4 mai. 2012.

WALTY, Ivete L. C. (2007). Mobilidades culturais: o exemplo das revistas alternativas urbanas. Scripta, Belo Horizonte, v. 11, n. 20, p. 195-204. Disponível em: <http:/ / migre.me/2gIvJ>. Acesso em: 5 maio 2012.

Recebido em outubro de 2011. Aprovado em março de 2012.

\section{resumo/abstract}

\section{O jogo autor-leitor na literatura do agora}

Everton Vinicius de Santa

As questões envolvendo autoria, leitor, obra e suas relações têm sido o foco de muitas abordagens teóricas ao longo da tradicional crítica literária, que já tem bem definidos os papéis dessas três instâncias. Contudo, ao tratarmos das atuais práticas de literatura, sobretudo se considerarmos a evidente imersão de autores e leitores no ciberespaço, percebemos que esses autores contemporâneos necessitam de uma exposição midiática e usam dessa exposição para justificar suas escolhas na criação da obra literária ou mesmo para aproximar-se de seu leitor, figura que daria sentido ao seu trabalho. Nessa perspectiva, Um erro emocional, de Cristovão Tezza, permite-nos transitar entre esse novo jogo autor-leitor à luz de uma exposição midiática evidenciada pelos ambientes virtuais e por questões teóricas que colocam essas instâncias em níveis distintos. Ainda que focado na literatura do agora, percebo que, embora essa aproximação entre autor e leitor não seja inédita, fica evidente a influência do ciberespaço nesse processo.

Palavras-chave: Cristovão Tezza, literatura contemporânea, autoria, crítica literária, ciberespaço. 


\section{The author-reader game in contemporary literature}

Everton Vinicius de Santa

The issues involving authorship, the reader, the literary work and their relationships have been the focus of many theoretical approaches over traditional literary criticism, which already has clearly defined the roles of these three instances. However, in addressing the current practices of literature, especially considering the apparent immersion of authors and readers in cyberspace, I realize that these authors need a contemporary media exposure and use this to justify their choices in the creation of literary works or even to getting closer to their reader, person that would make their work gain significance. In this sense, Um erro emocional, by Cristovão Tezza, allow us to investigate this new author-reader game from, in the light of media exposure as evidenced by the virtual environments, and the theoretical issues that put these instances at different levels. Though focused on contemporary literature, I realize that although this approach between author and reader is not unprecedented, the influence of cyberspace in this process is evident.

Keywords: Cristovão Tezza, contemporary literature, authorship, literary criticism, cyberspace. 